\title{
Sodium, Rubidium and Cesium lons Adsorption by Prussian Blue(PB)
}

\author{
Tan Guo ${ }^{1, *}$ a , Shan Yun ${ }^{1, b}$, Huaju Li ${ }^{1, c}$, Xiufang Zhu', d, Xiaoyan Gao1, e \\ 1 Jiangsu Provincial Engineering Laboratory for Advanced Materials of Salt Chemical Industry, \\ Huaiyin Institute of Technology, Huai'an, Jiangsu, 223003, China \\ aguotan@hyit.edu.cn, byunshan@hyit.edu.cn, chuajuli@hyit.edu.cn, dxiufangzhu@hyit.edu.cn, \\ egaoxiaoyan@hyit.edu.cn
}

${ }^{*}$ Corresponding author. E-mail: guotan@hyit.edu.cn

\begin{abstract}
Keywords: Sodium, Rubidium; Cesium, Prussian blue, Adsorption
Abstract: The adsorption of alkali metal ions onto prepared Prussian blue (PB) was investigated in single-element solutions. The released quantities of $\mathrm{K}^{+}$constitutive of $\mathrm{PB}$ were measured in course of adsorption time. Acidification occurred in these solutions because of decrease in $\mathrm{pH}$ values after adsorption. The PB was examined by Energy dispersive spectroscopy (EDS) technique. The results showed that the equilibrium adsorption capacities was in the sequence $\mathrm{Cs}^{+}>\mathrm{Rb}^{+}>\mathrm{Na}^{+}$. The mechanisms for the adsorption of $\mathrm{Na}^{+}, \mathrm{Rb}^{+}$and $\mathrm{Cs}^{+}$onto $\mathrm{PB}$ were deduced comprehensively as ion exchange with $\mathrm{K}^{+}$and trapping through $\mathrm{H}^{+}$. The selectivity sequence was $\mathrm{Rb}^{+}>\mathrm{Cs}^{+} \geq \mathrm{Na}^{+}$for ion exchange with $\mathrm{K}^{+}$because of the ionic radius of $\mathrm{Rb}^{+}$similar to that of $\mathrm{K}^{+}$. The adsorption mechanism was dependent of ion trapping through $\mathrm{H}^{+}$leading to the sequence of $\mathrm{Cs}^{+}>\mathrm{Rb}^{+}>\mathrm{Na}^{+}$owing to the size of their hydrated radius.
\end{abstract}

\section{Introduction}

Prussian blue (PB) is a synthetic coordination compound, which has a face-centered cubic lattice structure. $\mathrm{PB}$ is typically specified as soluble (e.g., $\mathrm{KFe}\left[\mathrm{Fe}(\mathrm{CN})_{6}\right] \cdot \mathrm{XH}_{2} \mathrm{O}, \mathrm{X}=14-16$ ) and insoluble $\left(\mathrm{Fe}_{4}\left[\mathrm{Fe}(\mathrm{CN})_{6}\right]_{3} \cdot \mathrm{XH}_{2} \mathrm{O}, \mathrm{X}=14-16\right)$, depending on the absence or presence of a monovalent ion in the lattice [1-3]. The soluble form is not truly soluble, but having tendency to form colloidal solution. Note that Prussian blue, which shows a high selectivity towards $\mathrm{Cs}^{+}$, can act as one of the most promising adsorbents for uptake of $\mathrm{Cs}^{+}[4,5]$. However, the mechanism of $\mathrm{Cs}^{+}$adsorption onto $\mathrm{PB}$ is still a controversial point as reported in the literatures [6-9]. Cesium is a group I alkali metal, and the alkali metal ions usually coexist under natural conditions due to their close similarity in physical and chemical characteristics $[10,11]$. Therefore, it is necessary to study the adsorption mechanism of the alkali metal ions, especially $\mathrm{Cs}^{+}$.

\section{Experimental}

Materials and preparation of $\mathbf{P B}$ adsorbent Sodium chloride, rubidium chloride, cesium chloride and potassium hexacyanoferrate were purchased from Tianjin Baishi Chemical Industry Co. Ltd., China. Iron (III) chloride was supplied from Sinopharm Chemical Reagent Co. Ltd., China. All reagents were analytical grade without further purification. All aqueous solutions were prepared with distilled water.

PB was synthesized by addition of $50 \mathrm{~mL} 0.6 \mathrm{~mol} \mathrm{~L}^{-1}$ aqueous solution of potassium hexacyanoferrate $\left(\mathrm{K}_{4}\left[\mathrm{Fe}(\mathrm{CN})_{6}\right]\right)$ to $40 \mathrm{~mL} 1 \mathrm{~mol} \mathrm{~L}^{-1}$ aqueous solution of iron(III) chloride $\left(\mathrm{FeCl}_{3}\right)$ under stirring. The resulting blue slurry was separated via filtration by a vacuum pump and washed several times with distilled till no ions. Finally, the separated precipitate was allowed to dry at room temperature to yield PB. The product was a mixture of soluble and insoluble PB with crystal water because of potassium and oxygen peaks as shown in Fig. 1 (a).

Adsorption experiment $0.1 \mathrm{~g}$ PB was added into an aqueous solution of $\mathrm{LiCl}, \mathrm{NaCl}, \mathrm{KCl}, \mathrm{RbCl}$ and $\mathrm{CsCl}\left(0.01 \mathrm{~mol} \mathrm{~L}^{-1}, 10 \mathrm{~mL}\right)$ individually in a sealable plastic tube. The tubes were shaken in a water bath with a speed of $150 \mathrm{rpm}$ at $25^{\circ} \mathrm{C}$. The solution samples were collected at timed intervals and the concentration of alkali metal ions was determined by an ICS-1100 ionic chromatograph. The 
adsorption amount of the alkali metal ions onto PB was calculated by the Eq. 1, where $q$ is the adsorption amount (mmol/g) at time $t, V$ the volume of the solution (L), $C_{0}$ and $C$ the metal ions concentration in the solutions before and after adsorption $(\mathrm{mmol} / \mathrm{L})$, and $m$ the mass of $\mathrm{PB}(\mathrm{g})$.

$$
q=\frac{V\left(C_{0}-C\right)}{m}
$$

\section{Results and discussion}

The adsorption kinetic curves for alkali metal ions onto PB were shown in Fig. 2 (a), where the order of adsorption ability was $\mathrm{Cs}^{+}>\mathrm{Rb}^{+}>\mathrm{Na}^{+}$, and $\mathrm{Li}^{+}, \mathrm{K}^{+}$were not adsorbed. Figure 1 (b), (c), (d) showed the EDS spectra of PB after adsorption the alkali metal ion. After adsorption there were sodium, rubidium and cesium peaks, indicating the successful adsorption.

Fig. 2 (b), (c), (d) showed the change in the concentration $(\Delta C)$ for $\mathrm{K}^{+}$compared to $\mathrm{Na}^{+}, \mathrm{Rb}^{+}$and $\mathrm{Cs}^{+}$in the process of adsorption. The mechanism of $\mathrm{Na}^{+}, \mathrm{Rb}^{+}$and $\mathrm{Cs}^{+}$adsorption onto insoluble $\mathrm{PB}$ was partially due to ion exchange with $\mathrm{K}^{+}$present in the crystal lattice, then a quantity of the released $\mathrm{K}^{+}$would be close to that of the adsorbed alkali metal ion. However, the results revealed that $\mathrm{K}^{+}$was released into solutions in less quantities compared to $\mathrm{Rb}^{+}$or $\mathrm{Cs}^{+}$, and nearly equality for $\mathrm{Na}^{+} . \Delta C$ of $\mathrm{K}^{+}$for $\mathrm{Na}^{+}, \mathrm{Rb}^{+}$and $\mathrm{Cs}^{+}$was $3.05 \mathrm{mmol} \mathrm{L}^{-1}, 5.00 \mathrm{mmol} \mathrm{L}^{-1}$ and $3.20 \mathrm{mmol} \mathrm{L}^{-1}$, respectively (Table.2). The highest exchange capacity for $\mathrm{Rb}^{+}$with $\mathrm{K}^{+}$was caused by their similar ionic radius [12].

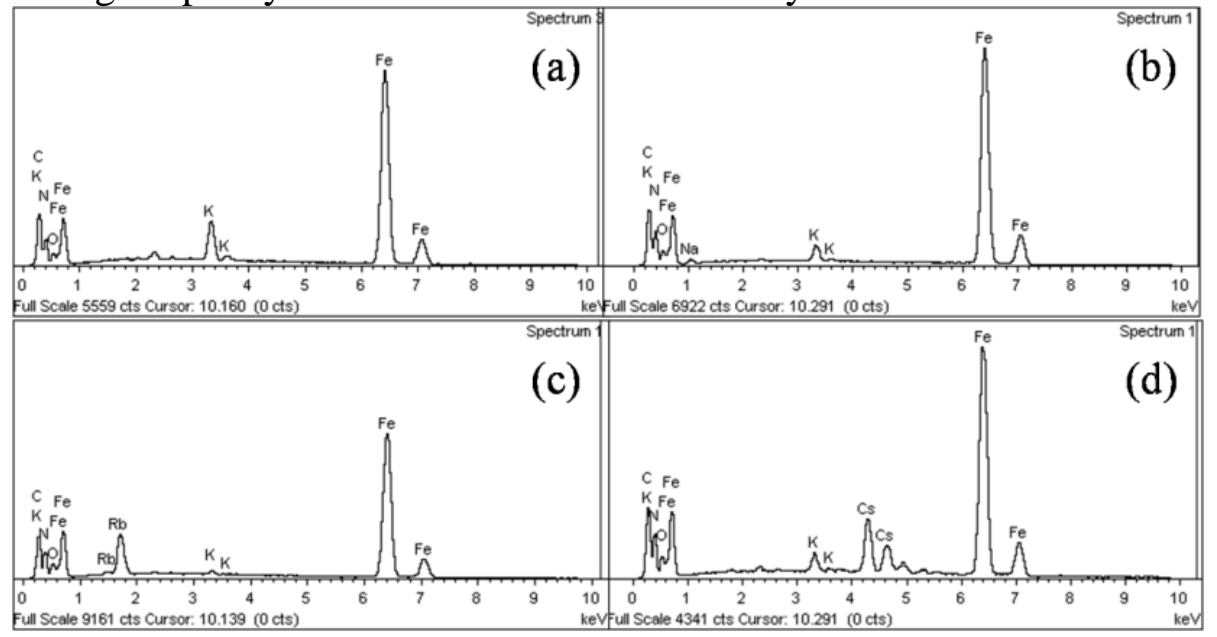

Fig. 1. EDS spectra of PB. (a) Before adsorption; (b) after adsorption of sodium;

(c) after adsorption of rubidium; (d) after adsorption of cesium.
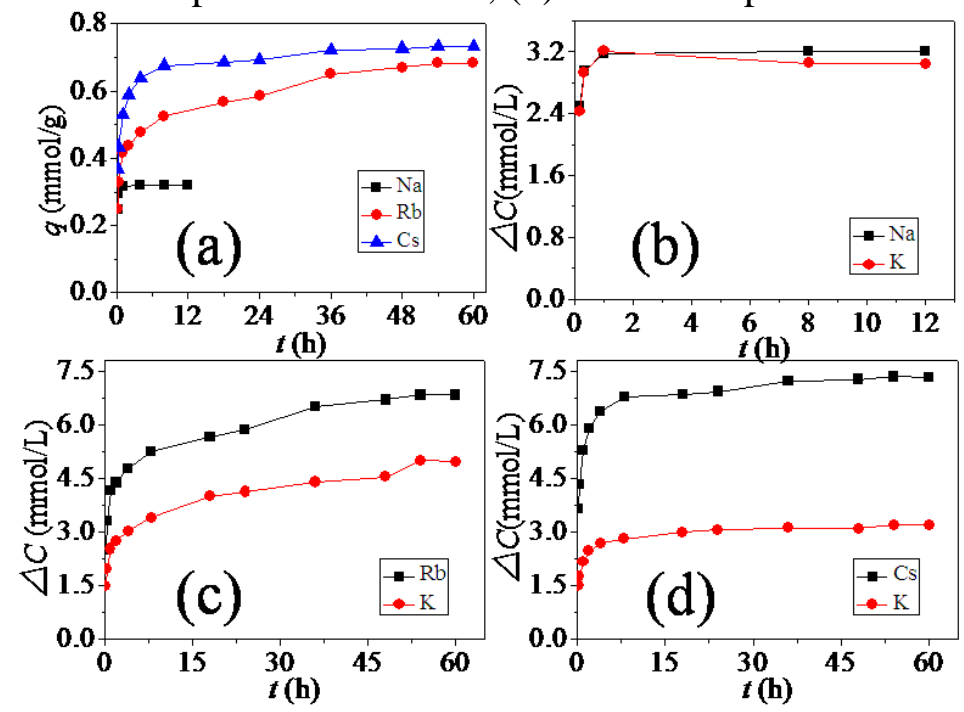

Fig. 2. Adsorption behavior of the alkali metal ions onto PB.

(a) the adsorption amount as a function of contact time; (b) $\Delta C\left(\mathrm{~K}^{+}\right)$compared to $\Delta C\left(\mathrm{Na}^{+}\right)$; 
(c) $\Delta C\left(\mathrm{~K}^{+}\right)$compared to $\Delta C\left(\mathrm{Rb}^{+}\right) ;(\mathrm{d}) \Delta C\left(\mathrm{~K}^{+}\right)$compared to $\Delta C\left(\mathrm{Cs}^{+}\right)$.

The $\mathrm{Rb} / \mathrm{K}, \mathrm{Cs} / \mathrm{K}$ exchange gravely deviated from a $1 / 1$ stoechiometry that $\mathrm{PB}$ possessed positive charges, while negative for the solution, so there should be other ions to maintain neutral. $\mathrm{Cl}^{-}$made no contributions in that the concentration of it was kept constant before and after adsorption determined by mercurimetry. Changes of solution in $\mathrm{pH}$ were measured using a Seven-multi $\mathrm{pH}$ Meter as listed in Table 1. The results showed that, before and after sorption, acidification of the solutions occurred. We can conclude that there was an ionic exchange reaction between $\mathrm{H}^{+}$and alkali metal ions, especially for $\mathrm{Rb}^{+}, \mathrm{Cs}^{+}$. In this mechanism, $\mathrm{Rb}^{+}$or $\mathrm{Cs}^{+}$was trapped via dissociation of water molecules expressed as the Eq. 2 and Eq. 3.

$$
\begin{aligned}
& \mathrm{H}_{2} \mathrm{O} \text { (solution) }+\mathrm{Cs}^{+} \mathrm{Cl}^{-} \text {(solution) } \rightarrow \text { PB- } \mathrm{Cs}^{+}-\mathrm{OH}^{-}+\mathrm{H}^{+} \mathrm{Cl}^{-} \text {(solution) } \\
& \mathrm{PB}-\mathrm{H}_{2} \mathrm{O} \text { (crystal water) }+\mathrm{Cs}^{+} \mathrm{Cl}^{-}(\text {solution }) \rightarrow(\mathrm{PB}-\mathrm{OH})^{-}-\mathrm{Cs}^{+}+\mathrm{H}^{+} \mathrm{Cl}^{-} \text {(solution) }
\end{aligned}
$$

The increased value of $\mathrm{H}^{+}$and $\mathrm{K}^{+}$concentration was approximately equal to the reduced value of the alkali metal ions concentration, namely $\Delta C\left(\mathrm{M}^{+}\right) \approx \Delta C\left(\mathrm{~K}^{+}\right)+\Delta C\left(\mathrm{H}^{+}\right)$(Table 2$)$, where $\mathrm{M}$ denoted $\mathrm{Na}, \mathrm{Rb}$ or Cs. The trapping ability of PB for alkali metal ions followed the order of $\mathrm{Cs}^{+}>\mathrm{Rb}^{+}>\mathrm{Na}^{+}$ according to the value of $\Delta C\left(\mathrm{H}^{+}\right)$, which was explained by hydrated radius with $\mathrm{Cs}^{+}<\mathrm{Rb}^{+}<\mathrm{Na}^{+}$ [13-15] and $\mathrm{Cs}^{+}$probably more suitable for PB cubic lattice structure.

Table $1 \mathrm{pH}$ of solution before and after adsorption

\begin{tabular}{cccc}
\hline & solution of $\mathrm{NaCl}$ & solution of $\mathrm{RbCl}$ & solution of $\mathrm{CsCl}$ \\
\hline before adsorption & 6.291 & 6.576 & 7.003 \\
after adsorption & 3.475 & 2.724 & 2.396 \\
\hline
\end{tabular}

Table 2 Changes of concentration before and after adsorption

\begin{tabular}{cccc}
\hline & $\begin{array}{c}\text { solution of } \mathrm{NaCl} \\
\left(\mathrm{mmol} \mathrm{L}^{-1}\right)\end{array}$ & $\begin{array}{c}\text { solution of } \mathrm{RbCl} \\
\left(\mathrm{mmol} \mathrm{L}^{-1}\right)\end{array}$ & $\begin{array}{c}\text { solution of CsCl } \\
\left(\mathrm{mmol} \mathrm{L}^{-1}\right)\end{array}$ \\
\hline$\Delta C\left(\mathrm{M}^{+}\right)$ & 3.21 & 6.83 & 7.34 \\
$\Delta C\left(\mathrm{~K}^{+}\right)$ & 3.05 & 5.00 & 3.20 \\
$\Delta C\left(\mathrm{H}^{+}\right)$ & 0.33 & 1.89 & 4.02 \\
\hline
\end{tabular}

\section{Summary}

We had quantitatively demonstrated the mechanism of $\mathrm{Na}^{+}, \mathrm{Rb}^{+}$and $\mathrm{Cs}^{+}$adsorption onto $\mathrm{PB}$ depend on ion exchange with $\mathrm{K}^{+}$and trapping through $\mathrm{H}^{+}$. The ionic radius of $\mathrm{Rb}^{+}$was similar to that of $\mathrm{K}^{+}$ leading to the selectivity sequence of $\mathrm{Rb}^{+}>\mathrm{Cs}^{+} \geq \mathrm{Na}^{+}$for ion exchange, whereas the sequence of adsorption for trapping was $\mathrm{Cs}^{+}>\mathrm{Rb}^{+}>\mathrm{Na}^{+}$owing to the size of their hydrated radius.

\section{Acknowledgements}

This study was financially supported by Opening Funding of Jiangsu Provincial Engineering Laboratory for Advanced Materials of Salt Chemical Industry (contract No: SF201507).

\section{References}

[1] J. Balmaseda, E. Reguera, J. Fernández, A. Gordillo and H. Yee-Madeira: J. Phys. Chem. Solids Vol. 64 (2003), p. 685-693.

[2] H.J. Buser, D.Schwarzenbach, W. Petter and A. Ludi: Inorg. Chem. Vol.16 (1977), p. 2704-2710.

[3] F. Herren, P. Fischer, A. Ludi and W. Haelg: Inorg. Chem. Vol.19 (1980), p. 956-959. 
[4] A.Kitajima, H. Tanaka, N. Minami, K. Yoshino and T. Kawamoto: Chem. Lett. Vol. 41 (2012), p. 1473-1474.

[5] T. Sasaki and S. Tanaka: Chem. Lett. Vol. 41 (2012): p. 32-34.

[6] P. Dreuw, J. Forster and H. Ney: J. Hazard.Mater. Vol. 217 (2012), p. 85-91.

[7] C. Thammawong, P. Opaprakasit, P. Tangboriboonrat and P. Sreearunothai: J. Nanoparticle Res. Vol. 15 (2013), p. 1-10.

[8] A.K. Vipin, B. Hu and B. Fugetsu: J. Hazard.Mater. Vol. 258 (2013), p. 93-101.

[9] H. Yang, L. Sun, J. Zhai, H. Li, Y. Zhao and H. Yu: J. Mater. Chem. A, Vol. 2 (2014), p. 326-332.

[10] P.A. Helmke, D.L. Sparks, D.L. Sparks and A.L. Page: Methods Soil Analysis. Part 3-Chemical methods (1996) p. 551-574.

[11] A.S. Relman: Yale J. Biol. Med. Vol. 29 (1956), p. 248-262.

[12] T.Simonsson and R. Sjöback: J. Biol. Chem. Vol. 274 (1999), p. 17379-17383.

[13] X. Ma and M. Pawlik: J. colloid Interf. Sci. Vol. 289 (2005), p. 48-55.

[14] P.C.F. Pau, J. Berg, and W. McMillan: J. Phys. Chem. Vol. 94 (1990), p. 2671-2679.

[15] H.Sakuma and K. Kawamura: Geochim. Cosmochim. Ac. Vol. 5 (2011), p. 63-81. 